\title{
ANALYSIS OF LAMINAR FILM BOILING IN BOUNDARY LAYER FLOWS WITH APPRECIABLE RADIATION
}

\author{
HSU-CHIEH YEH and WEN-JEI YANG \\ Dept. of Mech. Eng. \\ The University of Michigan, \\ Ann Arbor (Mich.), U.S.A.
}

\begin{abstract}
Summary
This paper presents the theoretical study of the heat transfer and friction characteristics in the natural convection film boiling on an inclined surface and a sphere, the forced convection film boiling over a horizontal plate, and the stagnation flow film boiling when radiation is appreciable. The boiling liquid is either at the saturation temperature or subcooled. The two phase flow and heat transfer problems have been formulated exactly within the framework of boundary layer theory with the consideration of the shear stress and vapor velocity at the liquid-vapor interface. Through the use of the similarity transformation expressions are obtained to determine the vapor film thickness, skin friction, and heat transfer rate. It is disclosed that the presence of surface radiation results in an increase in the heat transfer rate and a decrease in the skin friction.
\end{abstract}

\section{Nomenclature}

a constant defined with $U_{\infty}=a x$ for stagnation flow

$A$ physical parameter, (15f)

$B \quad$ physical parameter, $(7 \mathrm{~g})$

$B_{1} \quad$ physical parameter, (15f)

$C_{\mathrm{p}} \quad$ specific heat

$D$ physical parameter, (13c)

$E \quad$ physical parameter, defined as $h_{\mathrm{fg}} \operatorname{Pr} C_{\mathrm{p}}^{-1}\left(T_{\mathrm{w}}-T_{\mathrm{s}}\right)^{-1}$

$F$ temperature variable, (9c) and (18d) for natural convection film boiling and (25c) and (28b) for forced convection film boiling

$f \quad$ velocity variable, (9b) and (18c) for natural convection film boiling and $(25 \mathrm{~b})$ for the forced convection film boiling

$g$ gravitational acceleration

$h \quad$ local heat transfer coefficient, $q /\left(T_{\mathrm{w}}-T_{\mathrm{s}}\right)$ 
$h_{\mathrm{fg}} \quad$ latent heat of evaporation

$k \quad$ thermal conductivity

$N u \quad$ Nusselt number

Pr Prandtl number

Re Reynolds number

$p \quad$ pressure

$q \quad$ local heat flux from wall to vapor

$R \quad$ radius of sphere

$T$ temperature: $T_{\mathrm{w}}=$ wall temperature; $T_{\mathrm{s}}=$ saturated temperature; $T_{\infty}=$ free stream temperature

$U_{\infty} \quad$ free stream velocity

$u \quad$ velocity component of vapor in $x$ direction

$v \quad$ velocity component of vapor in $y$ direction

$x \quad$ coordinate measuring distance along the plate from leading edge

$y \quad$ coordinate normal to plate

$\alpha \quad$ thermal diffusivity

$\alpha_{\mathbf{r}} \quad$ absorption coefficient of vapor

$\beta \quad$ coefficient of thermal expansion

$\delta$ thickness of vapor film, (8) and (18a) for natural convection film boiling and (24) for forced convection film boiling

$\varepsilon \quad$ emissivity

$\eta \quad$ similarity variable, (9a) and (18b) for natural convection film boiling and (25a) and (28a) for forced convection film boiling

$\eta_{\delta} \quad$ dimensionless vapor film thickness

$\theta$ dimensionless temperature defined as $\left(T-T_{\mathrm{s}}\right) /\left(T_{\mathrm{w}}-T_{\mathrm{s}}\right)$ for vapor film and $\left(T_{\mathrm{L}}-T_{\infty}\right) /\left(T_{\mathrm{s}}-T_{\infty}\right)$ for liquid layer.

$\nu \quad$ kinematic viscosity

$\rho \quad$ density

$\rho_{\mathbf{r}} \quad$ refractivity

$\sigma \quad$ Stefan-Boltzmann constant

$\phi \quad$ angle of inclination or $x / R$

$\psi \quad$ stream function, (9b) and (18c) for natural convection film boiling and (25b) and (28b) for forced convection film boiling

Subscripts

Unsubscripted quantities: vapor phase

L liquid phase

r radiation

s at saturated state

w wall surface

$\infty$ free stream

Superscripts

"', ",', differentiation with respect to $\eta$ 


\section{§ 1. Introduction}

Film boiling is characterized by a vapor blanket covering the entire heated surface. It frequently occurs when the operation of jets or rockets involves the contact of a boiling liquid with high temperature surfaces or in the boiling of mercury especially at high heat fluxes. Film boiling may occur also if cryogenic fluids are used to cool hot surfaces. Since at high temperature differences, the film boiling is the normal type of heat transfer between the heated surface and the liquid, it is therefore of a definite scientific and practical interest.

In stable film boiling heat is transferred from a heating surface by conduction through the vapor film and by boiling convection from the surface of the film to the surrounding liquid. Superimposed on this heat flow path is the contribution of radiation to the total heat transfer. There are a few empirical equations being proposed to estimate the total surface conductance for film boiling when radiation is appreciable. However these equations are poor in accuracy and limited in application. This motivates the study of heat transfer and skin friction characteristics in both natural- and forced convection film boiling through the application of the boundary layer theory. Natural convection film boiling over a vertical plate and forced convection film boiling over a horizontal plate are investigated in [1]. This paper is the extension of [1] to include more twodimensional and axisymmetrical flows and to demonstrate the generality of the method of analysis for solving laminar film boiling problems.

Previous studies [2-9] of film boiling have been concerned with the situation where all motions are induced by gravity forces and where forced convection is absent. Such a process is usually called natural convection film boiling. Bromley [2] and Ellion [3] analyzed laminar film boiling on a vertical plate under the assumption of negligibly small inertia forces and convective effects. Hsu and Westwater [4] studied analytically and experimentally film boiling in both laminar and turbulent regions. McFadden and Grosh [5] solved the boundary layer equation for the vapor film and Cess [6], by means of the integral technique, solved the vapor and liquid boundary layer equations simultaneously. One feature common to previous analytical work is the assumption of zero interfacial velocity. Koh [7] analyzed the two phase flow problem with the con- 
sideration of the shear stress and vapor velocity at the liquid-vapor interface. The results showed that for water, the effect of the interfacial velocity is small over a wide range of practical interest. Under the assumption of the constancy of vapor properties, the analysis was extended by Sparrow and Cess [8] to include the effects of subcooling and then by Koh and Nilson [9] for the effects of simultaneous action of radiation in saturated film boiling. It is rather unfortunate that the similarity transformation of the conservation equations and the appropriate boundary conditions failed, because the new and old variables coexist in one of the resulting boundary conditions, (26) in [9]. In part of the present study, it is attempted to reexamine the problem treated in [9] by introducing a different transformation. Furthermore, consideration is given to the temperature variation of the vapor density.

Cess and Sparrow [10,11] analyzed the film boiling in forced convection boundary layer flows for the situation in which the liquid is at the saturation temperature or subcooled. Relative to the case of liquid flow, the skin friction is redured owing to film boiling. The heat transfer is found to increase as $(\Delta T)^{1 / 2}$.

In the present work attention is focused on the natural convection film boiling on an inclined plate and a sphere, the forced convection film boiling over a horizontal plate, and the stagnation flow film boiling. Consideration is given to the convective and radiational exchanges and the associated fluid motions in the vapor film and liquid layer. This is equivalent to solving a two phase boundary layer problem. In addition, a calculation is carried out for saturated film boiling.

\section{$\S 2$. Analysis}

2.1. Natural convection film boiling. The physical model and coordinate system selected for natural convection film boiling is shown in Fig. 1A. It consists of an isothermal inclined plate immersed in a large volume of liquid. It is assumed that the vapor forms a stable film over the surface. The liquid has a bulk temperature $T_{\infty}$ which is lower than the saturation temperature $T_{\mathrm{s}}$ prevailing at the liquid-vapor interface $y=\delta$. The temperature of the plate surface is prescribed as $T_{\mathrm{w}}$ and $T_{\mathrm{w}}>T_{\mathrm{s}}>T_{\infty}$.

It is assumed that under a stable film boiling condition there exists a laminar layer of vapor film adjacent to the plate surface. 


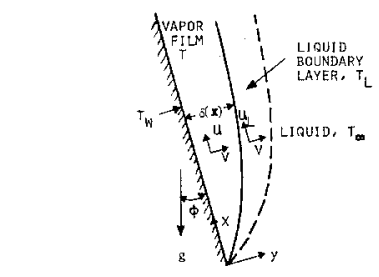

(A) natural-CONVECTION FILM BOILING ON AN INCLiNED PLATE

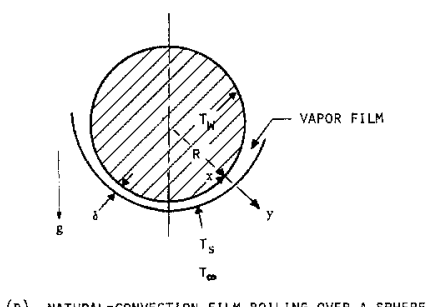

(B) NATURAL-CONVECTION FILM BOILING OVER A SPHERE

Fig. 1. Physical models and coordinates for natural convection film boiling.

Since the temperature of the plate and the vapor is relatively high, heat transfer takes place by convection as well as radiation.

With this assumption, the application of the conservation laws for mass, momentum, and energy to the vapor film produces as boundary layer equations for a gravity induced flow over the surface,

$$
\begin{gathered}
\frac{\partial u}{\partial x}+\frac{\partial v}{\partial y}=0 \\
u \frac{\partial u}{\partial x}+v \frac{\partial u}{\partial y}=v \frac{\partial^{2} u}{\partial y^{2}}+\frac{\rho_{\mathrm{L}}-\rho}{\rho} g \cos \phi \\
u \frac{\partial T}{\partial x}+v \frac{\partial T}{\partial y}=\alpha \frac{\partial^{2} T}{\partial y^{2}}+\frac{1}{\rho C_{\mathrm{p}}} \frac{\mathrm{d} q_{\mathrm{r}}}{\mathrm{d} y}
\end{gathered}
$$

where $\mathrm{d} q_{\mathbf{r}} / \mathrm{d} y$ may be determined as follows.

The vapor is assumed to be in thermodynamic equilibrium and behaves like a gray gas. If the radiation heat transfer between the vapor and the plate surface and the liquid-vapor interface is assumed equivalent to that of a slab of gray gas bounded by two parallel black boundaries, then the local radiation flux [9] may be 
expressed as

$$
\begin{aligned}
q_{\mathrm{r}}=2 \int_{\tau}^{\tau_{2}} \sigma T^{4} E_{2}(t-\tau) \mathrm{d} t-2 \int_{0}^{\tau} \sigma T^{4} E_{2}(\tau-t) \mathrm{d} t+ \\
+2 \sigma T_{\mathrm{s}}^{4} E_{3}\left(\tau_{2}-\tau\right)-2 \sigma T_{\mathrm{w}}^{4} E_{3}(\tau) .
\end{aligned}
$$

For an optically thin vapor for which $\tau_{2}$, the product of the absorption coefficient $\alpha_{\mathbf{r}}$ of the vapor and the thickness $\delta$ of the vapor film, is much less than unity, the functions $E_{2}$ and $E_{3}$ may be approximated by $1-\mathrm{O}(t)$ and $0.5-t+\mathrm{O}\left(t^{2}\right)$, respectively. If the temperature gradient of the vapor in the $y$ direction is much larger than that in the $x$ direction, then the net radiation to a unit volume of gas becomes

$$
\frac{\mathrm{d} q_{\mathrm{r}}}{\mathrm{d} y}=2 \alpha_{\mathrm{r}} \sigma\left(T_{\mathrm{w}}^{4}+T_{\mathrm{s}}^{4}-2 T^{4}\right)
$$

Eq. (3) may, then, be rewritten as

$$
u \frac{\partial T}{\partial x}+v \frac{\partial T}{\partial y}=\alpha \frac{\partial^{2} T}{\partial y^{2}}-4 \alpha_{\mathrm{r}} \sigma T_{\mathrm{s}}^{4}\left[\left(\frac{T}{T_{\mathrm{s}}}\right)^{4}-\frac{1}{2}-\frac{1}{2}\left(\frac{T_{\mathrm{w}}}{T_{\mathrm{s}}}\right)^{4}\right] .
$$

The mass and momentum conservation equations (2) and (3) also apply to the liquid layer, but now a subscript $\mathrm{L}$ is employed to identify the physical quantities of the liquid layer. Under assumption that the radiation from the plate surface and the vapor to the liquid is completely absorbed at the interface, the energy equation takes the form

$$
u_{\mathrm{L}} \frac{\partial T_{\mathrm{I}}}{\partial x}+v_{\mathrm{L}} \frac{\partial T_{\mathrm{L}}}{\partial y}=\alpha_{\mathrm{L}} \frac{\partial^{2} T_{\mathrm{L}}}{\partial y^{2}} .
$$

The appropriate boundary conditions are

$$
\begin{array}{rlrl}
y & =0 & & u=v=0, \quad T=T_{\mathrm{w}} \\
y=\infty & u_{\mathrm{L}}=0, \\
T_{\mathrm{L}}=T_{\infty} & \text { (for subcooled boiling only). }
\end{array}
$$

At the liquid-vapor interface it is required that the continuity of the tangential velocity, the tangential shear, the temperature, the mass flow crossing interface, and the heat flow crossing inter- 
face be preserved:

$$
\begin{gathered}
u_{\mathrm{L}}=u \\
\left(\mu \frac{\partial u}{\partial y}\right)_{\mathrm{L}}=\mu \frac{\partial u}{\partial y} \\
T_{\mathrm{L}}=T_{\mathrm{s}} \\
T=T_{\mathrm{S}} \\
\rho_{\mathrm{L}}\left(u \frac{\mathrm{d} \delta}{\mathrm{d} x}-v\right)_{\mathrm{L}}=\rho\left(u \frac{\mathrm{d} \delta}{\mathrm{d} x}-v\right) \\
\left(k \frac{\partial T}{\partial y}\right)_{\mathrm{L}}-k \frac{\partial T}{\partial y}+B+2 \alpha_{\mathbf{r}} \sigma \int_{0}^{\delta} T^{4} \mathrm{~d} y=\rho h_{\mathrm{fg}} \frac{\mathrm{d}}{\mathrm{d} x} \int_{0}^{\delta} u \mathrm{~d} y,
\end{gathered}
$$

where

$$
B=\frac{\sigma\left(T_{\mathrm{w}}^{4}-T_{\mathrm{s}}^{4}\right)}{(\rho / \varepsilon)_{\mathrm{L}}+1+(\rho / \varepsilon)_{\mathrm{w}}}
$$

is the net radiation flux between the surface and the liquid-vapor interface. Eq. (7f) is an energy balance at the interface which states that the sum of the local heat conduction and the net radiation gained at the interface is balanced by the heat of vaporization. The expression

$$
\rho \frac{\mathrm{d}}{\mathrm{d} x} \int_{0}^{\delta} u \mathrm{~d} y
$$

indicates the rate of vaporization per unit area. The contribution of the vapor radiation is included as the fourth term on the left hand side of (7f).

Now, effects may be directed toward finding solutions. It is assumed that the film thickness $\delta(x)$ takes the form

$$
\delta(x) \sim x^{1 / 4}\left(1+\sum_{m=1}^{\infty} a_{m} x^{m / 4}\right)
$$

where $a_{m}$ are the coefficients to be determined. The similarity variable is defined as

$$
\eta=c y /\left[x^{1 / 4}\left(1+\sum_{m=1}^{\infty} a_{m} x^{m / 4}\right)\right]
$$


where

$$
c=\begin{array}{ll}
\left.\frac{g \cos \phi}{4 v^{2}} \frac{\rho_{\mathrm{L}} R T_{\mathrm{S}}}{p}\right]^{1 / 4} & \text { for saturated liquid } \\
{\left[\frac{g \cos \phi}{4 \nu^{2}} \frac{\rho_{\mathrm{L}}-\rho}{\rho}\right]^{1 / 4}} & \text { for subcooled liquid, }
\end{array}
$$

when the constancy of vapor properties is assumed. The continuity equation can be satisfied by introducing a stream function such that $u=\partial \psi / \partial y$ and $v=-\partial \psi / \partial x$. We introduce the new variables

$$
\begin{array}{r}
\psi(\eta)=4 c v \sum_{n=0}^{\infty} x^{(n+3) / 4}\left(1+\sum_{m=1}^{\infty} a_{m} x^{m / 4}\right) f_{n}(\eta) \\
\theta(\eta)=\frac{T-T_{\mathrm{s}}}{T_{\mathrm{w}}-T_{\mathrm{s}}}=F_{0}(\eta)+x^{1 / 4} F_{1}(\eta)+x^{1 / 2} F_{2}(\eta)+x^{3 / 4} F_{3}(\eta)+\ldots
\end{array}
$$

From this and the expansion of

$$
1 /\left(1+\sum_{m=1}^{\infty} a_{m} x^{m / 4}\right)
$$

in a power series according to the binomial theorem, it follows

$$
\begin{gathered}
u=\frac{\partial \psi}{\partial y}=4 c^{2} \nu x^{1 / 2}\left(f_{0}^{\prime}+x^{1 / 4} f_{1}^{\prime}+x^{1 / 2} f_{2}^{\prime}+x^{3 / 4} f_{3}^{\prime}+\ldots\right) \\
v=-\frac{\partial \psi}{\partial x}=-4 c v \sum_{n=0}^{\infty} \sum_{m=0}^{\infty} a_{m} x^{1 / 4(m+n-1)}\left[\frac{m+n+3}{4} f_{n}-\eta f_{n}^{\prime} \frac{1}{4} \times\right. \\
\left.\times\left(1+a_{1} x^{1 / 4}+\left(2 a_{2}-a_{1}^{2}\right) x^{1 / 2}+\left(3 a_{3}-3 a_{1} a_{2}+a_{1}^{2}\right) x^{3 / 4}+\ldots\right)\right]
\end{gathered}
$$

where the primes represent differentiation with respect to the variable $\eta$. Owing to the employment of the binomial theorem in (10b), the restriction

$$
\left|\sum_{m=1}^{\infty} a_{m} x^{m / 4}\right|<1
$$

has been imposed on the solution.

The transformations (8), (9), and (10) may also be applied to the 
liquid layer provided that $c_{\mathrm{L}}$ and $\theta_{\mathrm{L}}$ are defined as

$$
\begin{array}{ll}
c_{\mathrm{L}}=\left[\frac{g \cos \phi}{4 v_{\mathrm{L}}^{2}} \frac{T_{\mathrm{s}}-T_{\infty}}{T_{\infty}}\right]^{1 / 4} & \text { for subcooled liquid } \\
c_{\mathrm{L}}=\left[\frac{g \cos \phi}{4 \nu_{\mathrm{L}}^{2}} \frac{\rho_{\mathrm{L}}-\rho}{\rho}\right]^{1 / 4} & \text { for saturated liquid } \\
\theta_{\mathrm{L}}=\frac{T_{\mathrm{L}}-T_{\infty}}{T_{\mathrm{s}}-T_{\infty}} &
\end{array}
$$

With the introduction of the transformations into the conservation eqs. (1) to (5), followed by collecting similar forms in $x$, one gets the following sets of simultaneous ordinary differential equations for both the vapor film and liquid layer.

For the vapor film:

$$
\begin{aligned}
& f_{0}^{\prime \prime \prime}+3 f_{0} f_{0}^{\prime \prime}-2\left(f_{0}^{\prime}\right)^{2}+\frac{1+\frac{T_{\mathrm{w}}-T_{\mathrm{s}}}{T_{\mathrm{s}}} F_{0}}{}=0 \\
& f_{1}^{\prime \prime \prime}+3 f_{0} f_{1}^{\prime \prime}-5 f_{0}^{\prime} f_{1}^{\prime}+4 f_{0}^{\prime \prime} f_{1}+\frac{\frac{T_{\mathrm{w}}-T_{2}}{T_{\mathrm{s}}} F_{1}}{T_{\mathrm{w}}-T_{2}} F_{1} \\
& f_{2}^{\prime \prime \prime}+3 f_{0} f_{2}^{\prime \prime}-6 f_{0}^{\prime \prime \prime} f_{2}^{\prime}+5 f_{0}^{\prime \prime} f_{2}+\frac{a_{0} f_{0}^{\prime \prime}}{\frac{T_{\mathrm{s}}}{\prime \prime}-} \\
& \quad-\left(a_{1} f_{0}+4 f_{1}\right) f_{1}^{\prime \prime}+3\left(f_{1}^{\prime}\right)^{2}-a_{1} f_{0}^{\prime \prime} f_{1}-\left(3 a_{1}^{2}-2 a_{2}\right) f_{0}^{\prime \prime \prime}+ \\
& \quad+\left(a_{1}^{2}-2 a_{2}\right) f_{0} f_{0}^{\prime \prime} .
\end{aligned}
$$

The underlined terms which result from the buoyancy force term in the momentum equation contribute to the coupling of the energy and momentum equations, i.e. the coupling of the $f$ and $F$ functions. The terms having the coefficient $\left(T_{\mathrm{w}}-T_{\mathrm{s}}\right) / T_{\mathrm{s}}$ are absent if the constancy of fluid properties is assumed in the vapor film. For the liquid layer, the underlined terms in (12a), (12b), and (12c) must be replaced by $F_{0}, F_{1}$, and $F_{2}$, respectively.

$$
\begin{aligned}
& \frac{1}{P r} F_{0}^{\prime \prime}+3 f_{0} F_{0}^{\prime}=0 \\
& \frac{1}{P r} F_{1}^{\prime \prime}+3 f_{0} F_{1}^{\prime}-f_{0}^{\prime} F_{1}=\frac{2 a_{1}}{P r} F_{0}^{\prime \prime}-F_{0}^{\prime}\left(a_{1} f_{0}-4 f_{1}\right)
\end{aligned}
$$




$$
\begin{aligned}
& \frac{1}{P r} F_{2}^{\prime \prime}+3 f_{0} F_{2}^{\prime}-2 f_{0}^{\prime} F_{2}- \\
& -\frac{D\left[\left(1+\frac{T_{\mathrm{w}}-T_{\mathrm{s}}}{T_{\mathrm{s}}} F_{0}\right)^{4}-\frac{1}{2}-\frac{1}{2}\left(\frac{T_{\mathrm{w}}}{T_{\mathrm{s}}}\right)^{4}\right]}{}= \\
& =\frac{2 a_{1}}{P r} F_{1}^{\prime \prime}-\left(a_{1} f_{0}+4 f_{1}\right) F_{1}^{\prime}+f_{1}^{\prime} F_{1}-\frac{1}{P r}\left(3 a_{1}^{2}-2 a_{2}\right) F_{0}^{\prime \prime}- \\
& -\left(5 f_{2}+a_{1} f_{1}+2 a_{2} f_{0}-a_{1}^{2} f_{0}\right) F^{\prime},
\end{aligned}
$$

where

$$
D=4 \alpha_{\mathrm{r}} \sigma \frac{T_{\mathrm{s}}}{\left(T_{\mathrm{w}}-T_{\mathrm{s}}\right) \rho C_{\mathrm{p}} \nu c^{2}} .
$$

The underlined terms which result from the radiation term in the energy equation are for the vapor film only.

The boundary and matching conditions also may be rephrased in terms of the new variables. It must be noted that since the thickness $\delta(x)$ of the vapor film is small, one may take $\eta_{\mathrm{L}}=0$ at the liquidvapor interface for convenience. With the application of the transformations, there results:

1) Plate surface:

$$
f_{n}(0)=f_{n}^{\prime}(0)=0 ; \quad F_{0}^{\prime}(0)=1 \quad \text { and } \quad F_{n}(0)=0
$$

for all $n$ other than zero.

2) Liquid-vapor interface:

$$
\begin{gathered}
f_{n}^{\prime}\left(\eta_{\delta}\right)=f_{\mathrm{L} n}^{\prime}(0) \\
f_{0}^{\prime \prime}\left(\eta_{\delta}\right)=\left[\frac{\mu_{\mathrm{L}} \rho_{\mathrm{L}}}{\mu \rho}\right]^{1 / 2} f_{\mathrm{L} 0}^{\prime \prime}(0) \\
f_{1}^{\prime \prime}\left(\eta_{\delta}\right)-a_{1} f_{0}^{\prime \prime}\left(\eta_{\delta}\right)=\left[\frac{\mu_{\mathrm{L} \rho \mathrm{L}}}{\mu \rho}\right]^{1 / 2}\left[f_{\mathrm{L} 1}^{\prime \prime}(0)-a_{1} f_{\mathrm{L} 0}^{\prime \prime}(0)\right] \\
f_{2}^{\prime \prime}\left(\eta_{\delta}\right)-a_{1} f_{1}^{\prime \prime}\left(\eta_{\delta}\right)-\left(a_{1}^{2}-a_{2}\right) f_{0}^{\prime \prime}\left(\eta_{\delta}\right)= \\
=\left[\frac{\mu_{\mathrm{L} \rho \mathrm{L}}}{\mu \rho}\right]^{1 / 2}\left[f_{\mathrm{L} 2}^{\prime \prime}(0)-a_{1} f_{\mathrm{L} 1}^{\prime \prime}(0)+\left(a_{1}^{2}-a^{2}\right) f_{\mathrm{L} 0}^{\prime \prime}(0)\right] \\
F_{\mathrm{L} 0}(0)=1 \text { and } F_{\mathrm{L} n}(0)=0 \text { for all } n \text { other than zero } \\
F_{n}\left(\eta_{\delta}\right)=0
\end{gathered}
$$




$$
f_{n}\left(\eta_{\delta}\right)=\left[\frac{\mu_{\mathrm{L}} \rho_{\mathrm{L}}}{\mu \rho}\right] f_{\mathrm{L} n}(0)
$$

$3 E f_{0}\left(\eta_{\delta}\right)=-F_{0}^{\prime}\left(\eta_{\delta}\right)+A F_{\mathrm{L} 0}^{\prime}(0)$

$$
\begin{aligned}
& 4 E\left[f_{1}\left(\eta_{\delta}\right)+a_{1} f_{0}\left(\eta_{\delta}\right)\right]=-\left[F_{1}^{\prime}\left(\eta_{\delta}\right)-a_{1} F_{0}^{\prime}\left(\eta_{\delta}\right)\right]+ \\
& +A\left[F_{\mathrm{L} 1}^{\prime}(0)-a_{1} F_{\mathrm{L} 0}^{\prime}(0)\right]+B_{1} \\
& 5 E\left[f_{2}\left(\eta_{\delta}\right)+a_{1} f_{1}\left(\eta_{\delta}\right)+a_{2} f_{0}\left(\eta_{\delta}\right)\right]= \\
& =-\left[F_{2}^{\prime}\left(\eta_{\delta}\right)-a_{1} F^{\prime}\left(\eta_{\delta}\right)+\left(a_{1}^{2}-a_{2}\right) F_{0}^{\prime}\left(\eta_{\delta}\right)\right]+ \\
& +A\left[F_{\mathrm{L} 2}^{\prime}(0)-a_{1} F_{\mathrm{L} 1}^{\prime}(0)+\left(a_{1}^{2}-a_{2}\right) F_{\mathrm{L} 0}^{\prime}(0)\right]+ \\
& +D \operatorname{Pr}_{0}^{\eta_{\delta}}\left(1+\frac{T_{\mathrm{w}}-T_{\mathrm{s}}}{T_{\mathrm{s}}} F_{0}\right)^{4} \mathrm{~d} \eta,
\end{aligned}
$$

where

$$
\begin{aligned}
A & =\frac{k_{\mathrm{L}} \mathcal{C}_{\mathrm{L}}}{k c}\left(\frac{T_{\mathrm{s}}-T_{\infty}}{T_{\mathrm{w}}-T_{\mathrm{s}}}\right) \quad \text { for subcooled boiling } \\
A & =0 \quad \text { for saturated boiling, } \\
B_{1}=B k^{-1}\left(T_{\mathrm{w}}-T_{\mathrm{s}}\right)^{-1} c^{-1} & \\
E & =\rho h_{\mathrm{fg}} \nu k^{-1}\left(T_{\mathrm{w}}-T_{\mathrm{s}}\right)^{-1}=h_{\mathrm{fg}} \operatorname{Pr}_{\mathrm{p}}^{-1}\left(T_{\mathrm{w}}-T_{\mathrm{s}}\right)^{-1} .
\end{aligned}
$$

For subcooled liquid the functions $f_{\mathrm{L} n}(0), f_{\mathrm{L} n}^{\prime}(0)$, and $f_{\mathrm{L} n}^{\prime \prime}(0)$ are replaced by

$$
\begin{aligned}
& \left(\frac{\rho_{\mathrm{L}}}{\rho_{\mathrm{L}}-\rho} \frac{T_{\mathrm{s}}-T_{\infty}}{T_{\infty}}\right)^{1 / 4} f_{\mathrm{L} n}(0) \\
& \left(\frac{\rho_{\mathrm{L}}}{\rho_{\mathrm{L}}-\rho} \frac{T_{\mathrm{s}}-T_{\infty}}{T_{\infty}}\right)^{1 / 2} f_{\mathrm{L} n}^{\prime}(0) \\
& \text { and } \\
& \left(\frac{\rho_{\mathrm{L}}}{\rho_{\mathrm{L}}-\rho} \frac{T_{\mathrm{S}}-T_{\infty}}{T_{\infty}}\right)^{3 / 4} f_{\mathrm{L} n}^{\prime}(0), \text { respectively. }
\end{aligned}
$$

In case the vapor density is assumed constant, $\rho_{\mathrm{L}}\left(T_{\mathrm{s}}-T_{\infty}\right) /$ $/\left(\left(\rho_{\mathrm{L}}-\rho_{\infty}\right) T\right)$ in the matching conditions must be replaced by unity.

3) Free stream:

$$
f_{\mathrm{L} 0}^{\prime}(\infty)=0
$$


and

$$
\begin{aligned}
& f_{\mathbf{L} n}^{\prime}(\infty)=0 \quad \text { for all } n \text { other than zero; } \\
& F_{\mathbf{L} n}(\infty)=0
\end{aligned}
$$

Fig. 1B shows the physical model for natural convection film boiling over a sphere with radius $R$. The governing equations and the boundary and matching conditions are identical with those of the previous case except that the continuity equation now reads

$$
\frac{\partial(u r)}{\partial x}+\frac{\partial(v r)}{\partial y}=0
$$

and $\phi$ is defined as $x / R$.

Now, the film thickness and the similarity variable are defined as

and

$$
\delta(x)=1+\sum_{m=1}^{\infty} a_{2 m} \phi^{2 m}
$$

respectively, where

$$
\eta=C y /\left(1+\sum_{m=1}^{\infty} a_{2 m} \phi^{2 m}\right)
$$

$$
\begin{array}{ll}
C=\left[\frac{g}{R \nu^{2}} \frac{\rho_{\mathrm{L}}-\rho}{\rho}\right]^{1 / 4} & \text { for vapor, } \\
C=\left[\frac{g}{R \nu_{\mathrm{L}}^{2}} \frac{\rho_{\mathrm{L}}-\rho}{\rho}\right]^{1 / 4} & \text { for saturated liquid, } \\
C=\left[\frac{g}{R \nu_{\mathrm{L}}^{2}} \frac{\rho_{\mathrm{L}}-\rho}{\rho}\right]^{1 / 4} & \text { for subcooled liquid. }
\end{array}
$$

The continuity equation may be satisfied by introducing

$$
\psi(\eta)=c v \sum_{m=0}^{\infty} \sum_{n=0}^{\infty} a_{2 m} f_{2 n+1} \phi^{2 m+2 n+1},
$$

where $a_{0}=1$, such that $u=r^{-1} \partial \psi / \partial y$ and $v=-\gamma^{-1} \partial \psi / \partial x$. The dimensionless temperature is defined as

$$
\theta(\eta)=\sum_{n=0}^{\infty} F_{2 n}(\eta) \phi^{2 n}
$$

When the transformations are applied to the conservation equa- 
tions (2), (3), and (4), there results

$$
\begin{gathered}
f_{1}^{2}-2 f_{1} f_{1}^{\prime \prime}-H-f_{1}^{\prime \prime \prime}=0 \\
4 f_{1}^{\prime} f_{3}^{\prime}-2 f_{1} f_{3}^{\prime \prime}-4 f_{1}^{\prime \prime} f_{3}+\left(\frac{1}{3}-2 a_{2}\right) f_{1} f_{1}^{\prime \prime}+2 a_{2} f_{1}^{\prime \prime}+J-f_{3}^{\prime \prime \prime}=0 \\
3 f_{3}^{\prime 2}-4 f_{3} f_{3}^{\prime \prime}+\frac{1}{3} f_{1} f_{3}^{\prime \prime}+\frac{1}{3} f_{1}^{\prime \prime} f_{3}+\frac{1}{45} f_{1} f_{1}^{\prime \prime}-K-2 a_{2} f_{1}^{\prime \prime} f_{3}-2 a_{2} f_{1} f_{3}^{\prime \prime}+ \\
+2 a_{2} f_{3}^{\prime \prime}+2 a_{2}^{2} f_{1} f_{1}^{\prime \prime}-4 a_{4} f_{1} f_{1}^{\prime \prime}+\left(2 a_{4}-3 a_{2}^{2}\right) f_{1}^{\prime \prime}-6 f_{5} f_{1}^{\prime \prime}+ \\
+6 f_{1}^{\prime} f_{5}^{\prime}-2 f_{1} f_{5}^{\prime \prime}-f_{5}^{\prime \prime \prime}=0
\end{gathered}
$$

where

$$
\begin{aligned}
& H=1, \quad J=\frac{1}{6}, \quad K=\frac{1}{120} \quad \text { for vapor film, } \\
& H=0, \quad J=0, \quad K=0 \quad \text { for saturated liquid, } \\
& H=F_{\mathrm{L} 0}, \quad J=F_{\mathrm{L} 2}-\frac{1}{6} F_{\mathrm{L} 0}, \\
& K=F_{\mathrm{L} 4}-\frac{1}{6} F_{\mathrm{L} 2}+\frac{1}{120} F_{\mathrm{L} 0} \quad \text { for subcooled liquid, } \\
& \frac{1}{P r} F_{0}+2 f_{1} F_{0}^{\prime}=D\left[\left(\frac{T_{\mathrm{w}}-T_{\mathrm{s}}}{T_{\mathrm{s}}} F_{0}^{\prime \prime}+1\right)^{4}-\frac{1}{2}-\frac{1}{2}\left(\frac{T_{\mathrm{w}}}{T_{\mathrm{s}}}\right)^{4}\right] \\
& \frac{1}{P r} F_{0}+2 f_{1} F_{0}^{\prime} \quad \text { for vapor } \\
& =0 \quad \text { for liquid, } \\
& \frac{1}{P r} F_{2}^{\prime \prime}-2 f_{1} F_{2}^{\prime}+2 f_{1} F_{2}^{\prime}+4 f_{3} F_{0}^{\prime}-\frac{1}{3} f_{1} F_{0}^{\prime}- \\
& -2 \frac{1}{P r} a_{2} F_{0}^{\prime \prime}+2 a_{2} f_{1} F_{0}^{\prime}= \\
& =D\left[-4\left(\frac{T_{\mathrm{w}}-T_{\mathrm{s}}}{T_{\mathrm{s}}} F_{0}+1\right)^{3} \frac{T_{\mathrm{w}}-T_{\mathrm{s}}}{T_{\mathrm{s}}}+2\left(\frac{T_{\mathrm{w}}}{T_{\mathrm{s}}}\right)^{3} \frac{T_{\mathrm{w}}-T_{\mathrm{s}}}{T_{\mathrm{s}}} b_{2}\right] \\
& \text { for vapor } \\
& =0 \quad \text { for liquid, } \\
& \frac{1}{P r} F_{4}^{\prime \prime}-4 f_{1}^{\prime} F_{4}+2 f_{1} F_{4}^{\prime}-2 f_{3}^{\prime} F_{2}+4 f_{3} F_{2}^{\prime}- \\
& -\frac{1}{3} f_{1} F_{2}^{\prime}+6 f_{5} F_{0}^{\prime}-\left(\frac{1}{3}-2 a_{2}\right) f_{3} F_{0}^{\prime}- \\
& -\left(\frac{1}{45}-4 a_{4}+2 a_{2}^{2}\right) f_{1} F_{0}^{\prime}-\frac{1}{P r}\left(2 a_{4}-3 a_{2}^{2}\right) F_{0}^{\prime \prime}-\frac{2}{P r} a_{2} F_{2}^{\prime \prime}= \\
& =-D\left[4\left(\frac{T_{\mathrm{w}}-T_{\mathrm{s}}}{T_{\mathrm{s}}} F_{0}+1\right)^{3} \frac{T_{\mathrm{w}}-T_{\mathrm{s}}}{T_{\mathrm{s}}} F_{4}+\right.
\end{aligned}
$$


$\left.+6\left(\frac{T_{\mathrm{w}}-T_{\mathrm{s}}}{T_{\mathrm{s}}} F_{0}+1\right)^{2}\left(\frac{T_{\mathrm{w}}-T_{\mathrm{s}}}{T_{\mathrm{s}}} F_{4}\right)^{2}\right] \quad$ for vapor

$$
=0 \quad \text { for liquid. }
$$

The boundary and matching conditions are

$$
\begin{gathered}
f_{2 n+1}(0)=f_{\mathrm{L} 2 n+1}(0)=f_{2 n+1}^{\prime}(0)=f_{\mathrm{L} 2 n+1}^{\prime}(0)=0 \\
F_{0}(0)=F_{\mathrm{L} 0}(0)=1, \quad F_{2}(0)=0, \quad F_{4}(0)=0, \quad \cdots \\
F_{\mathrm{L} 2 m}(0)=0 \quad \text { for all } m \text { other than zero } \\
F_{2 m}\left(\eta_{\delta}\right)=0 \\
f_{\mathrm{L} 2 n+1}^{\prime}(0)=\left(\frac{C}{C_{\mathrm{L}}}\right)^{2} \frac{\nu}{v_{\mathrm{L}}} f_{2 n+1}^{\prime}\left(\eta_{\delta}\right),
\end{gathered}
$$

where

$$
=1 \quad \text { for saturated liquid }
$$

$\left(\frac{C}{C_{\mathrm{L}}}\right)^{2} \frac{\nu}{\nu_{\mathrm{L}}}=\left[\frac{\rho_{\mathrm{L}}-\rho}{\rho} \frac{T_{\infty}}{T_{\mathrm{s}}-T_{\infty}}\right]^{1 / 2} \quad$ for subcooled liquid

$$
\begin{array}{rlr}
f_{\mathrm{L} 1}^{\prime \prime}(0) & =G f^{\prime \prime}\left(\eta_{\delta}\right) \\
f_{\mathrm{L} 3}^{\prime \prime}(0) & =a_{2} f_{\mathrm{L} 1}^{\prime \prime}(0)+G\left[f_{3}^{\prime \prime}\left(\eta_{\delta}\right)-a_{2} f_{1}^{\prime \prime}\left(\eta_{\delta}\right)\right] \\
f_{\mathrm{L} 5}^{\prime \prime}(0) & =a_{2} f_{\mathrm{L} 3}^{\prime \prime}(0)+\left(a_{4}-a_{2}^{2}\right) f_{\mathrm{L} 1}^{\prime \prime}(0)+G\left[f_{5}^{\prime \prime}\left(\eta_{\delta}\right)-a_{2} f_{3}^{\prime \prime}\left(\eta_{\delta}\right)-\right. \\
& \left.-\left(a_{4}-a_{2}^{2}\right) f_{1}^{\prime \prime}\left(\eta_{\delta}\right)\right], & \\
G & =\left[\frac{\mu \rho}{\mu_{\mathrm{L}} \rho_{\mathrm{I}}}\right]^{1 / 2} & \text { for saturated liquid }
\end{array}
$$

with

$$
\begin{aligned}
G= & {\left[\frac{\mu \rho}{\mu_{\mathrm{L} \rho \mathrm{L}}}\right]^{1 / 2}\left[\frac{\rho_{\mathrm{L}}-\rho}{\rho} \frac{T_{\infty}}{T_{\mathrm{s}}-T_{\infty}}\right]^{3 / 4} \text { for subcooled liquid, } } \\
A F_{\mathrm{L} 0}^{\prime}(0)- & F^{\prime}\left(\eta_{\delta}\right)+B_{1}+\frac{D}{2} \operatorname{Pr} \int_{0}^{\eta_{\delta}}\left(1+\frac{T_{\mathrm{w}}-T_{\mathrm{s}}}{T_{\mathrm{s}}} \theta_{0}\right)^{4} \mathrm{~d} \eta=E f_{1}\left(\eta_{\delta}\right) \\
A\left[F_{\mathrm{L} 2}^{\prime}(0)-\right. & \left.a_{2} F_{\mathrm{L} 0}^{\prime}(0)\right]-F_{2}^{\prime}\left(\eta_{\delta}\right)+a_{2} F_{0}^{\prime}\left(\eta_{\delta}\right)+ \\
& +2 D P r \int_{0}^{\eta_{\delta}}\left(1+\frac{T_{\mathrm{w}}-T_{\mathrm{s}}}{T_{\mathrm{s}}} F_{0}\right)^{3} \frac{T_{\mathrm{w}}-T_{\mathrm{s}}}{T_{\mathrm{s}}} F_{2} \mathrm{~d} \eta= \\
& =3 E\left[a_{2} f_{1}\left(\eta_{\delta}\right)+f_{3}\left(\eta_{\delta}\right)\right] \\
& F_{\mathrm{L} 2 m}(\infty)=0, \quad f_{\mathrm{L} 2 m}(\infty)=0 .
\end{aligned}
$$


It is important to restate that the analysis may be applied to both the saturated and subcooled film boiling. For the latter case, the functions $F_{\mathrm{L} n}$ and the parameter $A$ become identically zero because the liquid temperature is constant and equal to the saturation temperature, i.e. $T_{\mathrm{L}}\left(\eta_{\mathrm{L}}\right)=T_{\infty}=T_{\text {sat }}$.

Each set of differential equations for $f_{n}, f_{\mathrm{L} n}, F_{n}$, and $F_{\mathrm{L} n}$ requires ten of eleven boundary and matching conditions. The extra one as expressed by (15f) may be used for the evaluation of the thickness $\eta_{\delta}$ and the coefficients $a_{n}$.

Now, it is desirable to inspect the physical parameters governing the natural convection film boiling. There is a total of nine: $P r$, $P \gamma_{\mathrm{L}}, T_{\mathrm{w}} / T_{\mathrm{s}}, D,\left[(\rho \mu)_{\mathrm{L}} /(\rho \mu)\right]^{1 / 2},\left(\rho_{\mathrm{L}} /\left(\rho_{\mathrm{L}}-\rho\right)\right)\left(\left(T_{\mathrm{s}}-T_{\infty}\right) / T_{\infty}\right), A, B_{1}$, and $E$. Of these, the first four arise in connection with the differential equations (13) for the vapor film and liquid vapor, while the last six enter through the interface matching conditions. The parameter which appears only in the natural convection but not in the forced convection film boiling is $\left(\rho_{\mathrm{L}} /\left(\rho_{\mathrm{L}}-\rho\right)\right)\left(\left(T_{\mathrm{s}}-T_{\infty}\right) / T_{\infty}\right)$. This results from the consideration given to the temperature dependency of the vapor density. In the absence of the vapor and wall radiation, the governing parameters reduce to five: $\operatorname{Pr}, \operatorname{Pr}_{\mathrm{L}},\left[(\rho \mu)_{\mathrm{L}} /(\rho \mu)\right]^{1 / 2}$, $A$, and $E$.

2.2. Forced convection film boiling. The physical model and coordinate system are shown in Fig. 2A. The situation is the laminar

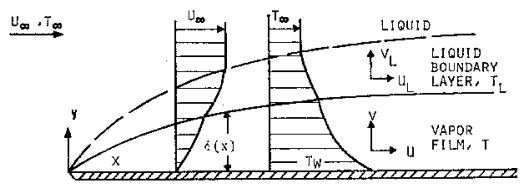

(A) FORCED CONVECTION FILM BOILING ON A fLAT PLATE

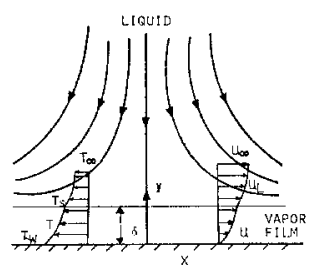

(B) STAGIATIOAN FILAA ROILIAIG IN THO-DHACHSIOHAL CLOW

Fig. 2. Physical models and coordinates for forced convection film boiling. 
boundary layer flow of a liquid with velocity $U_{\infty}$ over a flat plate. The liquid has a free stream temperature $T_{\infty}$ which is lower than the saturation temperature $T_{\mathrm{s}}$. The plate is maintained at the temperature $T_{\mathrm{w}}$, exceeding $T_{\mathrm{s}}$ enough for film boiling to occur on the plate.

With the same assumption as made in the previous case, the application of the conservation laws for mass, momentum, and energy to both vapor and liquid produces the boundary layer equations which are identical with (1), (2) with $g=0$, (4), and (5). Equation (5) is needed only for the subcooled film boiling since the liquid temperature is essentially constant for the saturated film boiling.

The boundary conditions at the surface of the plate $(y=0)$ and the matching conditions at the liquid-vapor interface $(y=\delta)$ are identical with (6a) and (7), respectively. However, far from the plate, in the bulk of the liquid, the velocity approaches $U_{\infty}$ and the temperature approaches its bulk temperature $T_{\infty}$. Therefore, eq. (6b) may be used as the boundary conditions provided that $u_{\mathrm{L}}$ is equated to $U_{\infty}$.

Utilizing the experience with the free convection film boiling from the previous section, we define the new dependent and independent variables for flow over a plate as

$$
\begin{gathered}
\delta(x) \sim x^{1 / 2}\left(1+\sum_{m=1}^{\infty} a_{m} x^{m / 2}\right) \\
\eta=\frac{y}{2}\left[\frac{U_{\infty}}{v x}\right]^{1 / 2} /\left(1+\sum_{m=1}^{\infty} a_{m} x^{m / 2}\right) \\
\psi(\eta)=2 c v \sum_{n=0}^{\infty} x^{(n+1) / 2}\left(1+\sum_{m=1}^{\infty} a_{m} x^{m / 2}\right) f_{n}(\eta) \\
\theta(\eta)=\sum_{n=0}^{\infty} x^{n / 2} F_{n}(\eta),
\end{gathered}
$$

where $c$ is defined as $(1 / 2)\left[U_{\infty} / v\right]^{1 / 2}$.

From this it follows that

$$
u=\frac{\partial \psi}{\partial y}=2 c^{2} v\left[f_{0}^{\prime}+x^{1 / 2} f_{1}^{\prime}+x f_{2}^{\prime}+x^{3 / 2} f_{3}^{\prime}+\ldots\right]
$$




$$
\begin{aligned}
v=-\frac{\partial \psi}{\partial x}=-2 c v & \sum_{m=0}^{\infty} \sum_{n=0}^{\infty} x^{1 / 2(m+n-1)}\left\{\frac{m+n}{2} f_{n}-\right. \\
& -\eta f_{n}^{\prime}\left[\frac{1}{2}+\frac{1}{2} a_{1} x^{1 / 2}+\left(a_{2}-\frac{1}{2} a_{1}^{2}\right) x+\right. \\
& \left.\left.+\frac{1}{2}\left(3 a_{3}-3 a_{1} a_{2}+a_{1}^{3}\right) x^{3 / 2}+\ldots\right]\right\} .
\end{aligned}
$$

Again, the restriction

$$
\left|\sum_{m=1}^{\infty} a_{m} x^{m / 2}\right|<1
$$

has been imposed on the solution owing to the application of the binomial theorem in (26b). When the transformations defined by (25) and (26) are introduced in the conservation equations (1), (2), (4), and (5) we obtain

$$
\begin{aligned}
& f_{0}^{\prime \prime \prime}+f_{0} f_{0}^{\prime \prime}=0 \\
& f_{1}^{\prime \prime \prime}+f_{0} f_{1}^{\prime \prime}-f_{0}^{\prime} f_{1}^{\prime}+2 f_{0}^{\prime \prime} f_{1}=2 a_{1} f_{0}^{\prime \prime \prime}-a_{1} f_{0} f_{0}^{\prime \prime} \\
& f_{2}^{\prime \prime \prime}+f_{0} f_{2}^{\prime \prime}-2 f_{0}^{\prime} f_{2}^{\prime}+3 f_{0}^{\prime \prime} f_{2}=2 a_{1} f_{1}^{\prime \prime \prime}-\left(2 f_{1}+a_{1} f_{0}\right) f_{1}^{\prime \prime}+ \\
& +\left(f_{1}^{\prime}\right)^{2}-a_{1} f_{0}^{\prime \prime} f_{1}+\left(2 a_{2}-3 a_{1}^{2}\right) f_{0}^{\prime \prime \prime}+\left(\frac{1}{2} a_{1}^{2}-a_{2}\right) f_{0} f_{0}^{\prime \prime} \\
& \frac{1}{P r} F_{0}^{\prime \prime}+f_{0} F_{0}^{\prime}=0 \\
& \frac{1}{P r} F_{1}^{\prime \prime}+f_{0} F_{1}^{\prime}-f_{0}^{\prime} F_{1}=\frac{2}{P r} a_{1} F_{0}^{\prime \prime}-\left(a_{1} f_{0}-2 f_{1}\right) F_{0}^{\prime} \\
& \frac{1}{P r} F_{2}^{\prime \prime}+f_{0} F_{2}^{\prime}-2 f_{0}^{\prime} F_{2}-D\left[\left(1+\frac{T_{\mathrm{w}}-T_{\mathrm{s}}}{T_{\mathrm{s}}} F_{0}\right)^{4}-\frac{1}{2}-\right. \\
& \left.-\frac{1}{2}\left(\frac{T_{\mathrm{w}}}{T_{\mathrm{s}}}\right)^{4}\right]=\frac{2}{P r} a_{1} F_{1}^{\prime \prime}-\left(a_{1} f_{0}+2 f_{1}\right) F_{1}^{\prime}+f_{1}^{\prime} F_{1}+ \\
& +\frac{1}{P \gamma}\left(2 a_{2}-3 a_{1}\right) F_{0}^{\prime \prime}-\left[3 f_{2}+a_{1} f_{1}+\left(2 a_{2}+a_{1}^{2}\right) f_{0}\right] F_{0}^{\prime} .
\end{aligned}
$$

With the introduction of the transformations, the appropriate boundary and matching conditions become identical with (13), (14), and (15) provided that the coefficients $3 E, 4 E, 5 E, \ldots$ of the left side terms of (14f) are replaced by $1 E, 2 E, 3 E$, respectively.

The physical model for stagnation film boiling in two-dimensional flow is shown in Fig. 2B. The free stream velocity $U_{\infty}$ can be expressed as $a x$, where $a$ is a constant. 
With the introduction of

$$
\begin{aligned}
\eta & =c y \\
\psi & =v c x f(\eta) \\
\theta(\eta) & =\frac{T-T_{\mathrm{s}}}{T_{\mathrm{w}}-T_{\mathrm{s}}} \\
u & =\frac{\partial X}{\partial Y}=\frac{1}{2} U_{\infty} t^{\prime},
\end{aligned}
$$

and

$$
v=-c f
$$

the momentum and energy equations, one obtains the following ordinary differential equations for both the vapor film and liquid layer:

$$
\begin{gathered}
f^{\prime \prime \prime}+f f^{\prime \prime}+4-\left(t^{\prime}\right)^{2}=0 \\
\frac{1}{P r} \theta^{\prime \prime}+f \theta^{\prime}=\frac{D}{2}\left[\left(1+\frac{T_{\mathrm{w}}-T_{\mathrm{s}}}{T_{\mathrm{s}}} \theta\right)^{4}-\frac{1}{2}-\frac{1}{2}\left(\frac{T_{\mathrm{w}}}{T_{\mathrm{s}}}\right)^{4}\right]
\end{gathered}
$$

where

$$
c=[a /(2 v)]^{1 / 2} .
$$

The boundary and matching conditions are:

1) Plate surface:

$$
f(0)=f^{\prime}(0)=0 ; \quad \theta(0)=1,
$$

2) Liquid-vapor interface:

$$
\begin{aligned}
& f^{\prime}\left(\eta_{\delta}\right)=f_{\mathrm{L}}^{\prime}(0), \quad f^{\prime \prime}\left(\eta_{\delta}\right)=\left[\frac{\mu_{\mathrm{L}} \rho_{\mathrm{L}}}{\mu \rho}\right]^{1 / 2} f_{\mathrm{L}}^{\prime \prime}(0), \quad \theta_{\mathrm{L}}(0)=1, \\
& f\left(\eta_{\delta}\right)=\left[\eta_{\mathrm{L}} \rho_{\mathrm{L}} / \mu \rho\right] f_{\mathrm{L}}(0) \\
& E f\left(\eta_{\delta}\right)=-\theta\left(\eta_{\delta}\right)+A \theta_{\mathrm{L}}^{\prime}(0)+B_{1}
\end{aligned}
$$

3) Free stream:

$$
f_{\mathrm{L}}^{\prime}(\infty)=2, \quad \theta_{\mathrm{L}}(\infty)=0
$$

The stagnation film boiling in three-dimensional flow was analyzed in an analogous manner. In the interest of brevity the results are not presented here. 
It is important to examine the physical parameters which govern the transport phenomena. There is a total of eight in the forced convection film boiling process. They are: $P r, P r_{\mathrm{L}}, T_{\mathrm{w}} / T_{\mathrm{s}}, D$, $\left[(\rho \mu)_{\mathrm{L}}\right]^{1 / 2} /(\rho \mu), A, B_{1}$, and $E$. Of these, $P r$ and $P \gamma_{\mathrm{L}}$ arise in connection with the differential equation (28) for the vapor film and liquid layer, respectively. The next two arise in connection with (28) for the vapor film induced by the vapor radiation. The last four enter through the matching conditions at the liquid-vapor interface. Among the four, $B_{1}$ is related to the surface radiation processes and $A$ is connected to the subcooling of the free stream.

In the absence of subcooling $P r_{\mathrm{L}}$ and $A$ cease to be the governing parameters. When the vapor radiation can be neglected, $D$ must be excluded from consideration as a parameter. When both the vapor and surface radiation can be neglected, $T_{\mathrm{w}} / T_{\mathrm{s}}, D$, and $B_{1}$ must be excluded. This leaves five parameters to govern the transport phenomena.

The dimensionless vapor film thickness $\eta_{\delta}$ and the coefficients $a_{m}$ are not considered as independent parameters because there is a unique relation among $\eta_{\delta}, a_{m}, A, B_{1}, D$, and $E$ as expressed by (15f).

\section{§ 3. Results}

3.1. Heat transfer. The local heat flux contributed by both radiation and convection at the plate surface is

$$
q=-k\left(\frac{\partial T}{\partial y}\right)_{y=0}-2 \alpha_{\mathbf{r}} \sigma \int_{0}^{\delta} T^{4} \mathrm{~d} y+B .
$$

When the Reynolds and Nusselt numbers, defined as $R e=U_{\infty} x / v$ and $N u=h x / k(N u=h R / k$ for sphere), respectively, are introduced and the heat flux is rephrased into the variables of the analysis, there follows:

1) For natural convection film boiling one gets

$$
\begin{aligned}
\frac{N u}{c x^{3 / 4}}= & -F_{0}^{\prime}(0)-\left[F_{1}^{\prime}(0)-a_{1} F_{0}^{\prime}(0)-B_{1}\right] x^{1 / 4}- \\
& -\left[F_{2}^{\prime}(0)-a_{1} F_{1}^{\prime}(0)+\left(a_{1}^{2}-a_{2}\right) F_{0}^{\prime}(0)+\right. \\
& \left.+\frac{1}{2} D \operatorname{Pr} \int_{0}^{\eta_{0}}\left(1+\frac{T_{\mathrm{w}}-T_{\mathrm{s}}}{T_{\mathrm{s}}} F_{0}\right)^{4} \mathrm{~d} \eta\right] x^{1 / 2}+\ldots
\end{aligned}
$$


for an inclined surface and

$$
\frac{N u}{c R}=-F_{0}^{\prime}(0)+B_{1}-\frac{1}{2} D \operatorname{Pr} \int_{0}^{\eta_{o}}\left[B_{0}^{4}+\left(B_{0}^{4} a_{2}+4 B_{0}^{3} B_{2}\right) \xi^{2}+\ldots\right] \mathrm{d} \eta
$$

for a sphere, where

$$
B_{0}=\left(T_{\mathrm{w}}-T_{\mathrm{s}}\right) F_{0}+T_{\mathrm{s}}, \quad B_{2}=\left(T_{\mathrm{w}}-T_{\mathrm{s}}\right) F_{2} .
$$

2) For forced convection film boiling on a horizontal surface

$$
\begin{aligned}
\frac{N u}{R e^{1 / 2}}= & -\frac{1}{2} F_{0}^{\prime}(0)-\frac{1}{2}\left[F_{1}^{\prime}(0)-a_{1} F_{0}^{\prime}(0)-B_{1}\right] x^{1 / 2}- \\
& -\frac{1}{2}\left[F_{2}^{\prime}(0)-a_{1} F_{1}^{\prime}(0)+\left(a_{1}^{2}-a_{2}\right) F_{0}^{\prime}(0)+\right. \\
& \left.+D \operatorname{Pr} \int_{0}^{\eta_{\mathrm{a}}}\left(1+\frac{T_{\mathrm{w}}-T_{\mathrm{s}}}{T_{\mathrm{s}}} F_{0}\right) \mathrm{d} \eta\right] x .
\end{aligned}
$$

3) For stagnation film boiling in two-dimensional flow

$$
\frac{N u}{c x}=-\theta^{\prime}(0)+B_{1}
$$

where $-\theta^{\prime}(0)$ and $B_{1}$ represent the heat transferred by conduction through the vapor film and by radiation from the surface, respectively. The leading terms of (36) and (38) represent the corresponding heat transfer results in the absence of the radiation exchange process. The second terms are the key terms in determining the effects of radiation exchange, since the contribution of the other terms is generally of secondary importance.

An investigation of (36) and (38) reveals that their second terms consist of $F_{0}^{\prime}(0), F_{1}^{\prime}(0), a_{1}$, and $B_{1}$ in which $F_{1}^{\prime}(0)$ and $a_{1}$ are interrelated to the parameter $B_{1}$ for the surface radiation by (13b) and (28b) and the second expression of (15f). Since the contribution due to the vapor radiation as represented by the parameter $D$ and its associated quantities $a_{2}$ and $F_{2}^{\prime}(0)$ first appears in the third terms of (36) and (38), the radiation effects on heat transfer are mainly due to the surface radiation, and the vapor radiation plays a rather unimportant role.

3.2. Skin friction. The shear stress exerted by the flowing fluid on the surface may be calculated by Newton's shearing formula $\tau_{\mathrm{w}}=$ 
$=-\mu(\partial w / \partial y)_{y=0}$. A dimensionless representation of the wall shear may be achieved by utilizing a friction coefficient defined as $\tau_{\mathrm{W}} /\left(\frac{1}{2} \rho U_{-\infty}^{2}\right)$. When this is evaluated in terms of the variables of the analysis, there results

$$
\begin{aligned}
\frac{\tau_{\mathrm{W}} R e^{1 / 2}}{\frac{1}{2} \rho U_{\infty}^{2}} & =\frac{1}{2}\left\{f_{0}^{\prime \prime}(0)+\left[f_{1}^{\prime \prime}(0)-a_{1} f_{0}^{\prime \prime}(0)\right] x^{1 / 2}+\right. \\
& \left.+\left[f_{2}^{\prime \prime}(0)-a_{1} f_{1}^{\prime \prime}(0)+\left(a_{1}^{2}-a_{2}\right) f_{0}^{\prime \prime}(0)\right] x+\ldots\right\}
\end{aligned}
$$

for forced convection film boiling over a horizontal plate,

$$
=\frac{1}{\sqrt{2}} f^{\prime \prime}(0)
$$

for stagnation film boiling in two-dimensional flow.

The leading term in (40a) represents the skin friction in the absence of the radiation exchange process. The second term is most important in determining the radiation effects.

Based on the similar arguments for heat transfer, the radiation effects on the skin friction are found to be caused mainly by the surface radiation. The vapor radiation exerts a negligible or secondary effect.

\section{§ 4. Numerical illustrations}

Eqs. (12) and (13) for natural convection film boiling over an inclined plate, (27) and (28) for forced convection film boiling over a horizontal plate, and (31) and (32) for stagnation film boiling in two-dimensional flow were numerically integrated (employing the Runge-Kutta method) in conjunction with their appropriate boundary conditions by means of an IBM 7090 digital computer. The first step is to prescribe the dimensionless vapor film thickness $\eta_{\delta}$. The calculation is carried out for the saturated boiling of water under atmospheric pressure with the neglect of gas radiation in the vapor film. This is justified as long as the vapor film is thin and the vapor pressure is not high. In other words, all radiation terms in the energy equations are neglected. Only the effects of radiation between the plate surface and the fluid interface, which appear in the boundary conditions, are taken into consideration. The range of the surface temperatures was from 280 to $3225^{\circ} \mathrm{F}$ (corresponding to $\eta_{\delta}$ from 0.6 to 1.6) and from 291 to $996^{\circ} \mathrm{F}$ (corresponding to $\eta_{\delta}$ from 0.2 to 


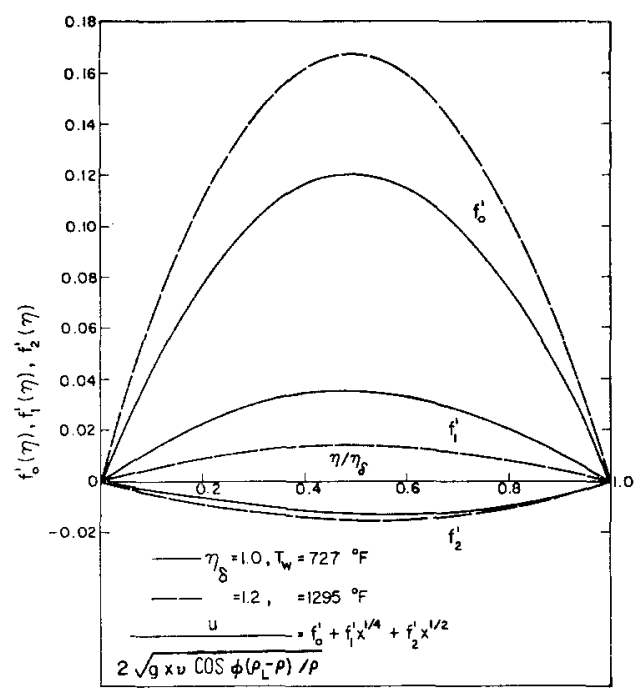

Fig. 3. Functions associated with vapor velocity in natural convection film boiling on an inclined plate for $T_{\mathrm{s}}=T_{\infty}=212^{\circ} \mathrm{F}$.

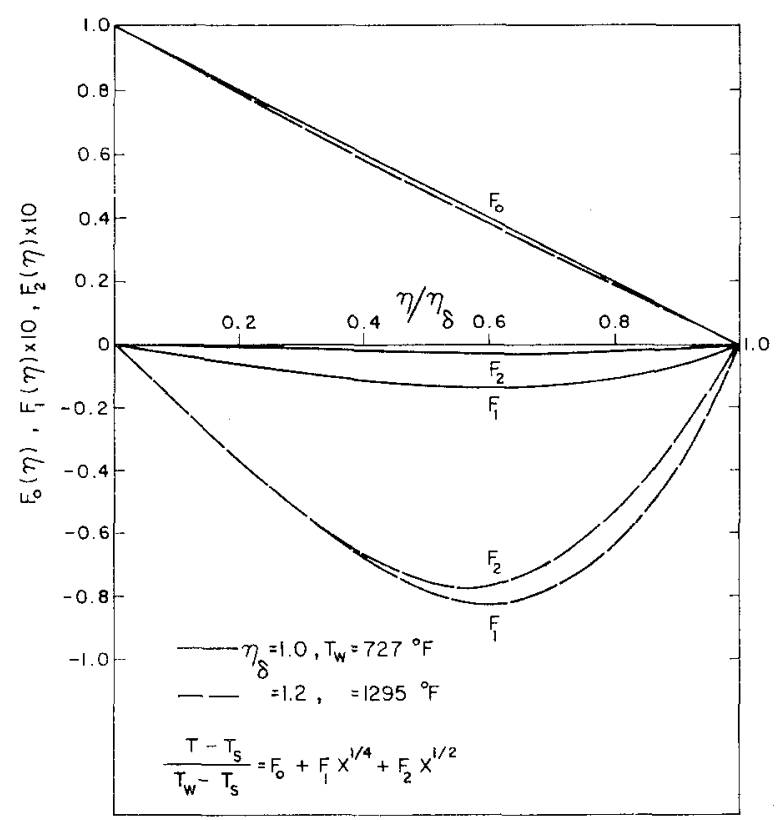

Fig. 4. Functions associated with vapor temperature in natural convection film boiling on an inclined flat plate for $T_{\mathrm{s}}=T_{\infty}=212^{\circ} \mathrm{F}$. 
0.6) for the natural and forced convection film boiling, respectively. The emissivities of the wall and liquid-vapor interface are taken to be unity. The typical velocity and temperature profiles are shown in Figs. 3-6.

Figs. 3 and 4 show the vapor velocity and temperature profiles in the natural convection film boiling for the special case of constant vapor properties. The terms $f_{0}^{\prime}$ and $F_{0}^{\prime}$ correspond to the velocity and temperature profiles, respectively, in the absence of radiation exchange. Since the magnitudes of $f_{2}^{\prime}$ and $F_{2}$ are rather of secondary importance in comparison with those of $f_{1}^{\prime}$ and $F_{1}$, it is observed from Figs. 3 and 4 that the presence of radiation increases the velocity profile and decreases the temperature profile. The effects are greater for higher wall temperature or thicker vapor film.

For forced convection film boiling, Fig. 5 illustrates that the velocity profile $f_{0}^{\prime}$ in the vapor film is practically linear in the absence of radiation. The effect of radiation is to increase the flow velocities in both vapor film and liquid boundary layer, and hence the skin friction is decreased at the plate surface. An increase in the wall temperature (or the vapor film thickness) or a decrease in the free stream velocity results in an increase in the radiation effect.

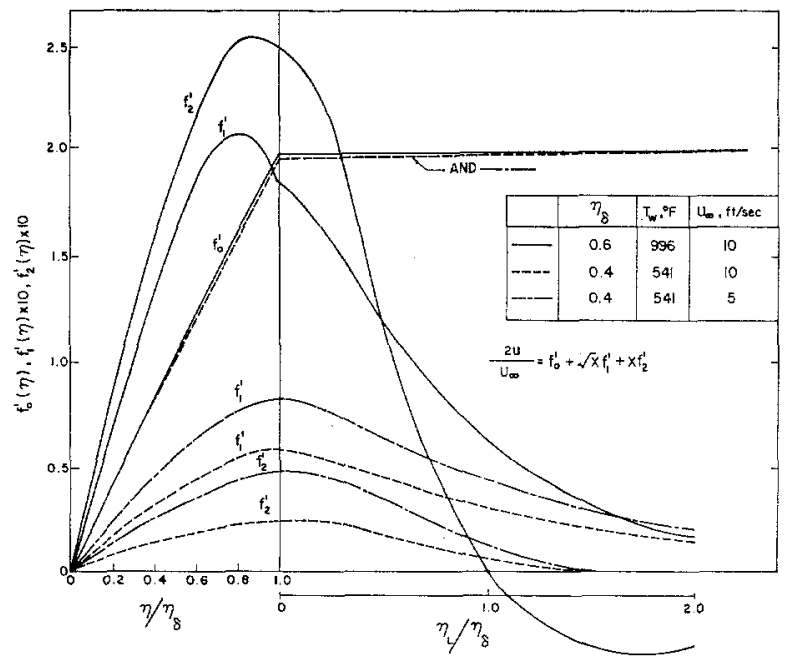

Fig. 5. Functions associated with velocity profiles in the vapor and liquid boundary layers for forced convection film boiling over a horizontal plate for $T_{\mathrm{s}}=T_{\infty}=212^{\circ} \mathrm{F}$. 


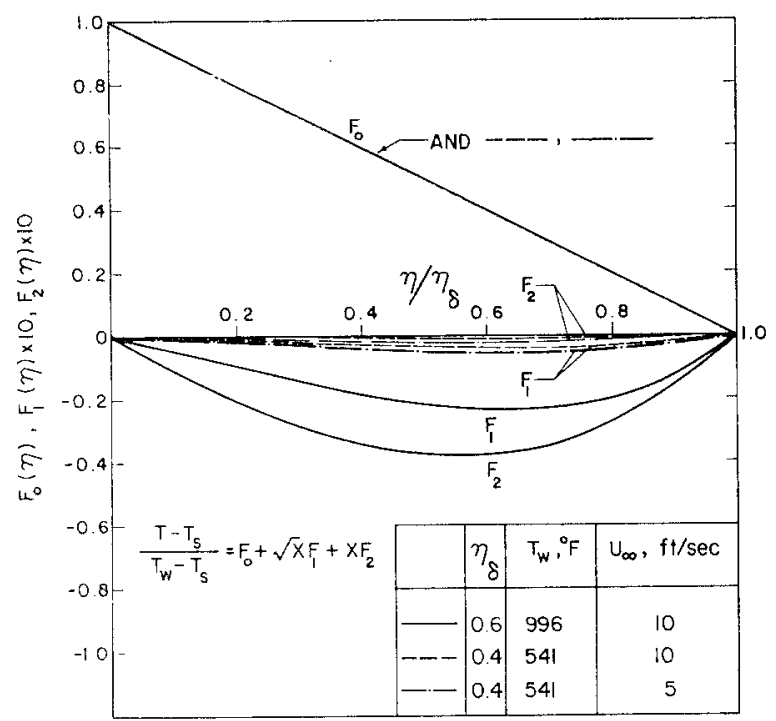

Fig. 6. Functions associated with vapor temperature in forced convection film boiling over a horizontal plate for $T_{\mathrm{s}}=T_{\infty}=212^{\circ} \mathrm{F}$.

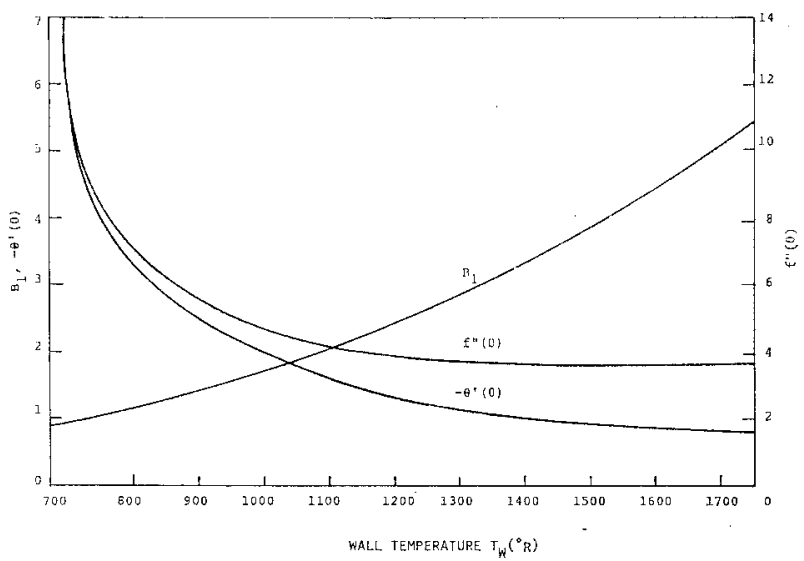

Fig. 7. Heat transfer and skin friction characteristics of stagnation film boiling in two-dimensional flow of water at atmospheric pressure.

Fig. 6 shows that the temperature distribution $F_{0}$ in the vapor film is practically linear in the absence of the radiation process. A simultaneous action of radiation is to decrease the vapor temperature, and hence the heat conduction is increased at the wall surface. As shown in Fig. 6, the radiation effects on the temperature profile 


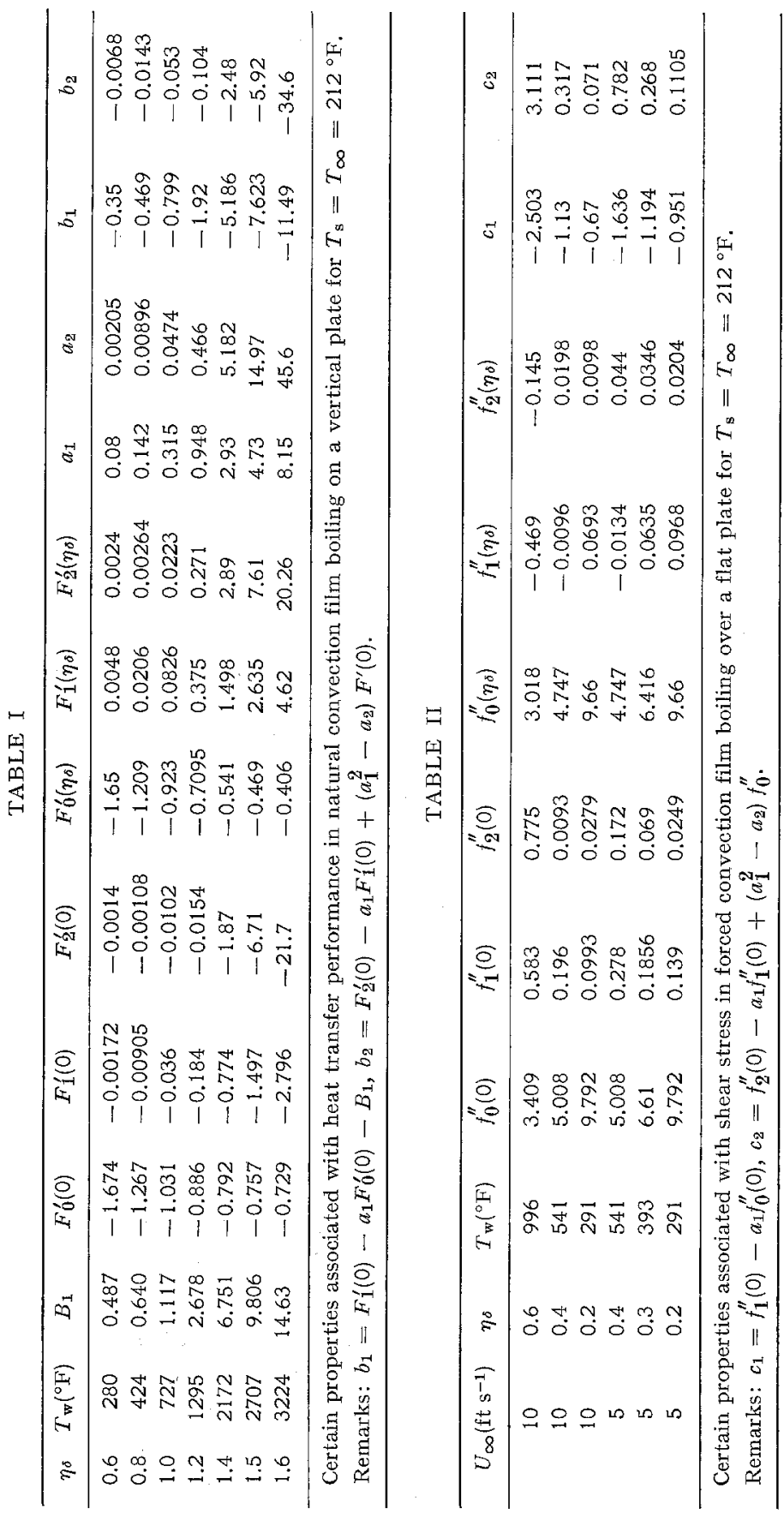

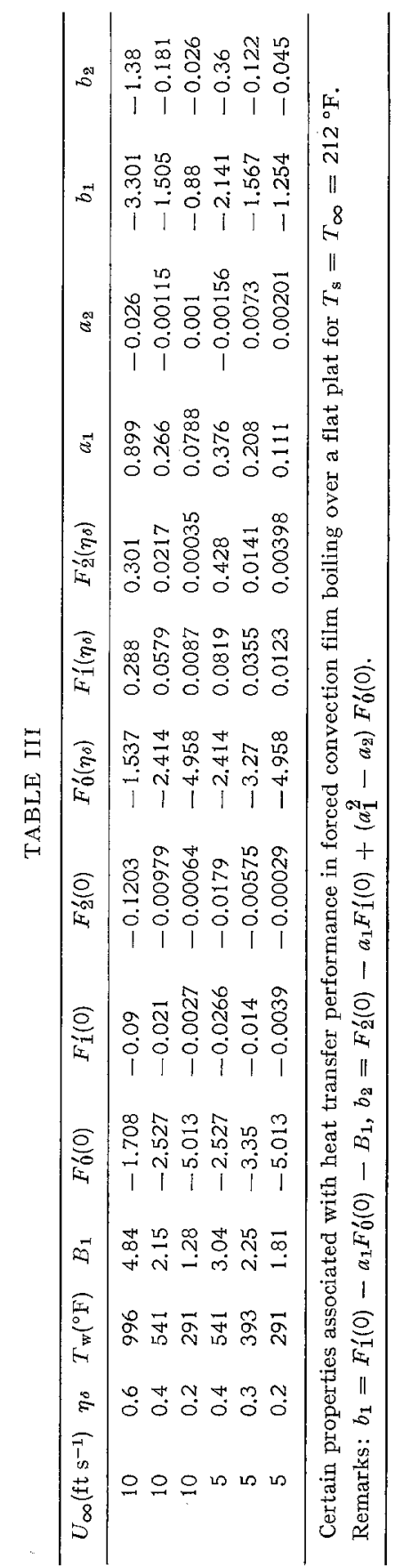


are larger for thick vapor film (or higher wall temperature) or for lower free stream velocity.

Fig. 7 shows the heat transfer and skin friction characteristics for the stagnation film boiling in two-dimensional flow of water at a velocity of $U_{\infty}=10 x \mathrm{ft} \mathrm{s}^{-1}$ under atmospheric pressure. It is seen in the figure that as the surface temperature increases from $212^{\circ} \mathrm{F}$, both skin friction $f^{\prime \prime}(0)$ and conduction through the vapor film $-\theta^{\prime}(0)$ decrease, while surface radiation $B_{1}$ increases. When the surface temperature exceeds $1000^{\circ} \mathrm{R}, B_{1}$ is larger than $-\theta^{\prime}(0)$ indicating that surface radiation becomes more important than conduction through the vapor film.

Tables I to III furnish important results for radiation effect on heat transfer performance and shear stress at the wall surface and the liquid-vapor interface. For the natural convection film boiling over a vertical plate, Table I indicates that the presence of radiation increases the heat transfer from the wall to the vapor and from the vapor to the interface. The radiation effects become greater for higher wall temperature or thicker vapor film. Tables II and III show that for forced convection film boiling over a horizontal plate, radiation increases the local Nusselt numbers and decreases the shear stresses at the wall surface and the liquid-vapor interface. An increase in the wall temperature or vapor film thickness or a decrease in the free stream velocity may contribute to an increase in the radiation effects.

\section{§ 5. Concluding remarks}

To replace the existing empirical equations which have been used for estimating the total surface conductance in film boiling expressions are now obtained for the determination of the heat transfer rate and skin friction in (i) the natural convection film boiling over an inclined surface and a sphere, (ii) the forced convection film boiling over a horizontal plate, and (iii) the stagnation flow film boiling when radiation is appreciable. The problems have been formulated exactly within the framework of boundary layer theory with the consideration of the shear stress and vapor velocity at the liquid vapor interface. The method of analysis may be extended to the natural- and forced convection film boiling over other surfaces of different geometry. The problems of film boiling on a surface having space dependent temperature may also be solved by the 
present method by expanding the surface temperature into an infinite series with respect to the depending space variable.

Received 19 September 1967

Final form 2 April 1968

\section{REFERENCES}

[1] Yeh Hsu-Chien and Wen-Jer YANG, Radiation Effects on Film Boiling in Naturaland Forced-Convection Boundary-Layer Flows, report No. 66-WA/HT-6, ASME Winter Meeting, New York 1966.

[2] Bromley, L. A., Chem. Eng. Progress 46 (1950) 221.

[3] Ellion, M. E., A Study of the Mechanism of Boiling Heat Transfer, Memo No. 2088, J PL, Cal. Inst. of Techn., Pasadena (Cal.) 1954.

[4] Hsu, Y. Y. and J. W. Westwater, Chem. Eng. Progress Symp. Ser. (Heat TransferStorrs) 56 (No. 30, 1960) 15.

[5] McFadden, P. W. and R. J. Grosh, Intern. J. Heat Mass Transf. 1 (1961) 325.

[6] Cess, R. D., Trans. ASME Ser. C 81 (1959) 1.

[7] KoH, S. C. Y., ASME J. Heat Transf. Ser. C 84 (1962) 52.

[8] Sparrow, E. M. and R. D. Cess, ASME J. Heat Transf. Ser. C 84 (1962) 149.

[9] KоH, J. C. Y. and T. W. Nilson, Simultaneous Convection, and Radiation in Laminar Film Boiling on Vertical Surfaces, report No. 63-HT-2, ASME, New York 1963.

[10] Cess, R. D. and E. M. Sparrow, ASME J. Heat Transf. Ser. C 84 (1962) 370.

[11] Cess, R. D. and E. M. Sparrow, ASME J. Heat Transf. Ser. C 84 (1962) 377. 